\title{
DISTORSI SEJARAH ISLAM PADA MASA AL-KHULAFĀ AR-RĀSYIDŪN DAN DAULAH UMAYYAH (Tinjauan Kritis Buku Ajar Sejarah Kebudayaan Islam Madrasah Aliyah)
}

\author{
Luthfi Romdhon dan Andri Permana \\ Gondangrejo, Cakru, Kencong, Jember \\ E-Mail: romdhon_apl@yahoo.co.id
}

\begin{abstract}
Distortion in the history of Islam has been occured since the first codification of the history of Islam which supported by Shi'ites historian such as Abu Mihnaf Lut bin Yahya and others. Distortion in modern era refers to hegemony of orientalism which has big influence and power in this field. Distortion was caused by religion, sect, money motive etc. This distortion spread from society to school. The distortion happened at Rashidun Caliphate's time, which was started by rebellion toward Usmān. The rebelllion cause Usmān death. That killing has great implications; Jamal and Siffin wars, Kharijites revolts, hatred from some groups toward Umayyad Caliphate and in other effects at ummah. This writing aims to find out a method in studying the history of Islam, distortion and its implications, different opinions between sahäbat and Islamic view toward it. Author applied in writing this thesis bibliography method with historic-philoshopic approach from datas and evidences. Based on datas and evidences, the author can conclude that methods at researching, writing and teaching history of Islam is very important to purify the history of Islam from distortion. Distortion means attempt to mislead datas or misinterpert intentionally or unintentionally. Distorsions have bad effects at Islam and ummah. If datas and histories are distorted, it will estrange people from Islam slowly which found out at some people and groups. Teaching history of Islam at schools which also distorted need to be totally reformed started from researching, writing and teaching method. The different opinions between șahābat because of the death of Usmān. Sahābat had different opinions about hastening or postponing qis̄ās to Usimān murderers which cause Jamal and Siffin wars. The implications of different opinions between șahābat have big influence in people creed toward șahābat from that day until now. It also causes hatred from some people and sects toward Umayyad Caliphate because Mu'äwiyah; founder Umayyad Caliphate has some different opinions with Ali-radiyallahu'anhuma-besides other hatred factors.
\end{abstract}

Keywords: The history of Islam, distortion, șahābat, al-khulafā ar-rāsyidūn, Umayyah.

\begin{abstract}
Abstrak: Distorsi sejarah Islam terjadi sejak masa awal penulisan sejarah Islam yang terutama dimotori oleh Syiah melalui periwayatan sejarawan seperti Abu Mihnaf Lut bin Yahya dan lainnya. Pada masa sekarang terutama karena hegemoni orientalisme yang begitu kuat. Distorsi tersebut terjadi karena motif agama, sekte, materi dan lainnya. Hal tersebut menyebar di masyarakat hingga level sekolah. Distorsi tersebut terutama pada fase khulafaurrasyidin dengan pemberontakan terhadap Usimān hingga ia terbunuh yang berimplikasi panjang; perang Jamal dan Siffin, pemberontakan Khawārij, kebencian sebagian kalangan kepada Daulah Umawiyyah dan efeknya yang lain di tubuh umat dalam banyak bidang. Penelitian ini bertujuan mengetahui cara orisinil dalam studi sejarah Islam untuk menangkal distorsi, distorsi dan dampaknya serta perselisihan diantara para șahābat dan pandangan Islam menyikapi perselisihan tersebut. Penelitian ini menggunakan metode penelitian bibliografi dengan
\end{abstract}


pendekatan historis-filosofis dari data yang didapatkan. Berdasar data dapat disimpulkan bahwa metode studi sejarah Islam penting dalam upaya menjaga kemurnian sejarah Islam dari distorsi. Distorsi itu sendiri bermakna upaya menghancurkan Islam terlepas sengaja atau tidak sengaja. Dampak distorsi berpengaruh pada Islam dan umat, ketika informasi dan sejarah yang diterima terdistorsi, hal itu akan menjauhkannya dari agama secara perlahan-perlahan sebagaimana yang terjadi pada sebagian kalangan. Pengajaran sejarah Islam di sekolah pun ikut terdistorsi yang menunjukkan urgensi perbaikan menyeluruh yang harus dimulai dari metode penelitian, penulisan dan pendidikan yang orisinil. Perselisihan antar șahāabat dipicu kematian Usmān yang terzalimi. Mereka berbeda ijtihad antara menyegerakan atau menunda qis̄ās yang menyebabkan terjadinya perang Jamal dan Siffin. Dampaknya di umat terasa terutama dalam masalah akidah terhadap șahābat sejak itu hingga sekarang. Hal tersebut juga mempengaruhi pandangan sebagian kalangan terhadap Daulah Umawiyyah mengingat posisi Mu'āwiyah; pendiri Daulah Umawiyyah yang berselisih dengan Ali -radiyallahu'anhumadisamping sebab-sebab kebencian yang lain.

Kata kunci: Sejarah Islam, distorsi, șaḥābat, al-khulafā ar-rāsyidūn, Umayyah.

\section{PENDAHULUAN}

Sejarah Islam mulai dikodifikasikan sejak masa Daulah Abbāsiyah (132-659 H) yang menggantikan Daulah Umayyah (41$132 \mathrm{H})^{1}$. Maklum diketahui permusuhan antara keduanya, hal itu mempengaruhi penulisan sejarah. Tidak heran Muhibbuddin al-Khațīb menjelaskan bahwa sejarawan dibagi menjadi tiga: Pertama, kelompok yang menggantungkan hidupnya dengan mendekati para pembenci Daulah Umayyah. Kedua, kelompok yang meyakini bahwa agama mereka tidak sempurna kecuali dengan mendiskreditkan Abu Bakar, Umar, Usman dan Bani Abdu Syams sebagai induk Bani Umayyah secara keseluruhan². Ketiga, kelompok yang netral dari muhaddisîn semisal Ibnu Jarîr, Ibnu 'Asākir, Ibnu Kasîir, Ibnu al-Aśîr, aż-Żahabî dan lainnya. Mereka mengumpulkan riwayat yang ada dari

1 Ta'lîq Muhịbuddīn al-Khațīb dalam Qāội Ibnu alArabî, Al'Awāṣsim min al-Qawāṣim, (Kairo: Matba'ah Salafiyah, Cet. 4, 1396 H), hlm. 177.

2 Karena itu terdapat seruan penulisan kembali sejarah Daulah Umayyah yang terzalimi. Lihat Hamdi Sāhîn, ad-Daulah al-Umawiyah al-Muftara Alaiha, (Kairo: Dār Al-Qāhirah li al-Kitab, 2001), hlm. 5; Muhammad Amaḥzūn, Harakah al-'Ilmiyyah fi Bilād al-Hijāz $f i$ al- 'Așri al-Umawi dalam Abhasं fi al-Da'wah wa atTārị̣ wa al-Ijtima', (Kairo: Dār as-Salām, Cet. 1, 1429 H), hlm. 51; Syakir al-Jaburî dan Nada Zaidan Khalaf, al-Ulūm ad-Dîniyyah wa Tațawwuruhā fi 'Așr al-Umawi dalam Majallah ad-Dirāsāt at-Tārikhiyyah wa al-Hadariyyah Vol. 5, No. 16: 122. berbagai kelompok dan sekte 3 . Khazanah yang sangat kaya ini bukanlah sejarah umat Islam, tapi bahan pokok yang kemudian disaring hingga sampai ke hakikat peristiwa yang sebenarnya terjadi.

Sebab di atas disamping sebab lain melahirkan distorsi sejarah Islam. Tonggak distorsi ini dimulai dari pemberontakan terhadap Uṡmān bin Affān hingga ia terbunuh. Implikasi pembunuhan ini panjang, bahkan Ibnu Taimiyah menyebut bahwa pembunuhan Uṡmān dan Husain; termasuk sebab terbesar dari fitnah, perselisihan dan permusuhan pada umat ini $^{4}$. Perselisihan Ali dengan Mu'āwiyah, Ali dengan 'Āisyah, pemberontakan Khawārij, fanatisme Syi'ah dan rentetan musibah lain yang menimpa umat dimulai dari musibah pembunuhan ini disamping faktor yang lain.

Akidah terhadap șậ̄bat sebagai pondasi keyakinan Islam menjadi goyah dan kabur.

Kaburnya pandangan tersebut diperparah distorsi penulisan sejarah, terutama pada fase al-Khulafā' ar-Rāsyidūn dan Daulah Umayyah. Distorsi ini menyebar di seluruh elemen umat tidak terkecuali

3 Ta'lîq Muhibbuddīn al-Khațīb dalam Qāḍ̂i Ibnu alArabî, Al'Awāṣim min al-Qawāṣim, hlm. 177.

4 Ibnu Taimiyyah, Majmu’ Fatāwa Jilid III, Tahqû̀q Khairî Sa'îd, (Kairo: Maktabah Taufiqiyyah, T.t.), hlm. 261. 
di sekolah. Penulis merasa terpanggil membuktikan adanya distorsi dalam pengajaran sejarah di sekolah terutama dalam dua fase ini.

Penelitian yang khusus membedah buku ajar SKI dan menjelaskan distorsi di dalamnya sepengetahuan penulis belum pernah ditulis sebelumnya. Walau tulisan yang membedah sejarah dua fase ini sangat banyak. Beberapa buku yang memiliki kemiripan dengan penelitian ini diantaranya al-'Awāșim min al-Qawāșim fi Tahqîq Mawāqif aș Șāhāābat ba'da Wafāti Nabi Shallallahualaihiwasallam milik Qāḍi Abu Bakar Ibnu al-Arabî (w. 543 H). Ibnu al-Arabî menceritakan sikap dari para șāhạābat setelah meninggalnya Rasulullah dan mendudukkan perselisihan yang ada di antara mereka.terutama pada masa Uṡmān, Ali, dan Mu'āwiyah bin Abi Sufyan. Huqbah min at-Tārîkh ma Baina Wafāti Nabi Shallahualaiwasallam ila Maqtal Husain RaḍiyallahuanhumilikUṡmān bin Muhammad al-Khāmîs. Tulisan ini menceritakan periode sejarah antara wafatnya Nabi sampai dengan meninggalnya Husain dengan fokus jawaban terhadap tuduhan dan syubhat masa Ușmān, Ali, Mu'āwiyah dan Yazid.

Taḥqîq Mawāqif as-Ṣāhābat Min Riwāyati Imam Tabarî wa al-Muhaddisîn tulisan Dr. Muhammad Amahzūn yang membas tentang sikap șāhāabat terhadap fitnah yang terjadi pada masa Ușmān dan Ali.

Marwiyyat Abu Mihnaff fi Tārîkh at-Tabarî milik Dr. Yahya bin Yahya. Penulis buku ini membuktikan kuatnya pengaruh riwayat Abu Miḥnaf yang Syiah dalam Tärîkh alUmam wa al-Muluk milik Ibnu Jarîr at-Tabarî (w. $310 \mathrm{H})$. Terdapat tulisan lain yang sejenis sebagai pembanding fakta dengan bahan di buku ajar SKI ini.

Penelitian lain yang berkaitan khusus dengan dengan pelajaran Sejarah Kebudayaan Islam lebih banyak yang menyoroti sisi usaha peningkatan kualitas pengajaran materi SKI, dari segi analisis pelajaran $^{5}$, usaha digitalisasi media

5 Haris Firmansyah, "Analisis Pembelajaran Sejarah Kebudayaan Islam Di Madrasah Aliyah Negeri 2 Pontianak". Tesis. Surakarta: Prodi Pendidikan Sejarah pengajaran $\mathrm{SKI}^{6}$, dan pengajaran SKI Kurikulum $\mathrm{KTSP}^{7}$. Sehingga tiga tulisan di atas fokus dalam metode pengajaran dan bukan analisis isi buku ajar SKI.

Tulisan disusun untuk mengetahui metode memahami sejarah Islam yang benar dan meluruskan distorsi di dalamnya, terutama masa al-Khulafā ar Rāsyidūn dan Daulah Umayyah.

\section{METODE PENELITIAN}

Lokasi dan subyek penelitian. Penelitian ini adalah bibliografi ${ }^{8}$ dengan membedah buku Perjalanan Sejarah Kebudayaan Islam 1 untuk Kelas XI Madrasah Aliyah Program Keagamaan yang ditulis oleh Sugiyono dan Moh. Sulaiman yang diterbitkan tahun 2013 oleh Aqila Solo; salah satu lini usaha Penerbit Tiga Serangkai Solo.

Pendekatan dan metode pengumpulan data. Penelitian ini menggunakan pendekatan historisfilosofis. Metode pengumpulan data dengan dokumentasi. ${ }^{9}$.Pengumpulan data dalam tulisan ini juga dilengkapi dengan wawancara.

Teknik analisis/interpretasi data. Analisis data dengan content analysis dilanjutkan dengan verifikasi dari data yang didapatkan.

Pascasarjana UNS, 2014.

6 Laily Nur Arifa dan Mariyatul Qibtiyah, "Digitalisasi Buku Ajar Sejarah Kebudayaan Islam Dalam Rangka Meningkatkan Motivasi Belajar Peserta Didik di MA Annur Bululawang”. Penelitian Dosen. Fakultas Tarbiyah UIN Malang, 2014.

7 Nurul Ummi Akhinah, "Pembelajaran Sejarah Kebudayaan Islam (SKI) berbasis KTSP (Kurikulum Tingkat Satuan Pendidikan) di kelas XI Agama MAN Yogyakarta II". Skripsi. Yogyakarta: Jurusan Pendidikan Agama Islam Fakultas Tarbiyah dan Keguruan, UIN Sunan Kalijaga, 2013.

8 Moh. Nazir, Metode Penelitian, (Jakarta: Ghalia Indonesia, 1988), hlm. 62; Sulasman, Metode Penelitian Sejarah, (Bandung: Pustaka Setia, Cet. 1, 2014), hlm. 87.

9 Kuntowijoyo, Pengantar Ilmu Sejarah, (Yogyakarta: Tiara Wacana, Cet. 1, 2013), hlm. 74. Hanya saja Kuntowijoyo khilaf dengan menyebutkan bahwa kata syajara dalam Bahasa Arab bermakna "terjadi", yang benar adalah tumbuh. Majma' Lugawî al-Masrî, Mu’jam al-Wajîz, hlm. 336. 


\section{HASIL DAN PEMBAHASAN}

1. Sejarah Islam; Definisi, Metode Studi, Metode Memahami Sejarah Șạ̣ābat dan Distorsi Sejarah Islam.

a. Definisi Sejarah Islam.

Ibnu Khaldūn mendefinisikan sejarah dari kedalaman makna dan ibrah yang terkandung walau secara dzahir sejarah hanya berisi kabar peristiwa dan bangsa, atau pendahulu manusia ${ }^{10}$.

b. Metode Studi Sejarah Islam

Terdapat beberapa kaidah dalam metode ini, yaitu 1) Kaidah Terkait Akidah dan Worldview, 2) Kaidah Terkait Referensi dan Sumber Pengambilan, 3) Kaidah Terkait Metode Paparan Sejarah.

c. Metode Memahami Sejarah ȘahāābatȘahābat adalah orang yang bertemu dengan Rasululluh, beriman kepadanya dan meninggal dalam keislamannya meskipun pernah murtad $^{11}$. Posisi mereka agung dalam Islam berdasar dalil syar'i yang sangat banyak dan Islam melarang keras mencela mereka dalam bentuk apapun yang akan merusak Islam dari porosnya.

Mengingat pentingnya hal tersebut, terdapat kaidah studi sejarah : 1) Hukum asal membahas perselisihan șahābat adalah menahan diri sebagaimana larangan Rasulullah, 2) tasiabbut dan klarifikasi menerima data $^{12}$, 3) Jika ada riwayat bernada celaan maka dipalingkan menuju jalan yang terbaik ${ }^{13}$, 4) Șaḥābat yang

10 Ibnu Khaldūn, Tārîkh Ibnu Khaldūn Jilid I, (Beirut: Dar al-Fikr, $1431 \mathrm{H})$, hlm. 6. Tārîkh Ibnu Khaldūn yang berjudul asli Diwan al-Mubtadā'wa al-Khabar fi Tãrîkh al-Arab wa al-Barbar wa Man 'Āsyarahum min Żawai asy-Sya'n al-Akbar terdiri atas beberapa bagian, namun yang paling terkenal dari Ibnu Khaldūn adalah bagian pertama dari sejarahnya ini yang terkenal dengan nama Muqaddimah Ibnu Khaldūn.

11 Ibnu Hajar, Nuzhah an-Nazar, Tahqî̀ Nuruddin 'Itr, (Kairo: Dar al-Bașảir, Cet.1, 1431 H), hlm. 112.

12 QS Al-Hujurāt 46: 6.

13 Ibnu Abi Zaid al-Qairuwānî, Muqaddimah Risālah Ibnu Abi Zaid Al-Qairuwānî dalam Qatf al-Jana alDanî, (Kairo-Dammām: Dar Ibnu Affān-Dar Ibnu alQayyim, Cet. 1, 1423 H), hlm. 48. berselisih semuanya berijtihad ${ }^{14}$, 5) Șaḥābat menyesali yang terjadi, 6) ma'sum; terlepas dari dari dosa hanyalah milik nabi dan rasul, 7) celaan pada șahāābat dengan kemasan ilmiah tidak mengubahnya dari celaan. Hukumnya kembali ke rincian awal.

d. Distorsi Sejarah Islam

Distorsi bermakna to tell people about a fact, statement etc. in a way that changes its meaning ${ }^{15}$. Padanannya dalam Islam tahrîf. Secara etimologis tahrîf berarti mencondongkan atau memiringkan ${ }^{16}$. Secara istilah berarti menggantinya dan atau merubah makna ${ }^{17}$. Dapat dikatakan tahrîf adalah usaha penyelewengan data baik dengan merubah lafaż atau merubah makna ${ }^{18}$.

\section{Distorsi Sejarah Islam Masa Khulafä' ar-Rāsyidîn dan Daulah Umayyah}

\section{Khulafā' ar-Rāsyidîn}

a. Khulafā' ar-Rāsyidūn; Paparan, Syubhat dan Jawaban
1) Abu Bakar
-radiyallahu'anhu- (11-13 H)
2) Umar bin al-Khațtab -radiyallahu'anhu- $(13-23 \mathrm{H})$

b. Syubhat dan Jawaban

Dikatakan bahwa Umar menerapkan pajak. Penulis menjawab bahwa masalah ini muncul karena kesalahan penerjemahan ke bahasa Indonesia, karena pungutan negara pada masa masa Umar hanya sebesar $10 \%$ kepada para pedagang ahlu al-harb, $5 \%$ untuk pedagang ahlu aż-żimmah, dan 2,5\% bagi pedagang kaum Muslim ${ }^{19}$.

14 An-Nawāwî. Al-Minhāj Syarh Șạih Muslim bin alHajjāj, Tahqîq Khalil Ma'mun Syîhạa, (Beirut : Dar alMa'rifah, Cet. 13, 1431 H), hlm. 145.

15 Della Summers (director), Longman Active Study Dictionary International Students Edition. (Essex: Pearson Education, 2004), hlm. 190.

16 Majma' Lugawî al-Masrî, al-Wajîz, hlm. 145.

17 Ibid.

18 Muhammad bin Șālị al-Us̉amîn, Syarh Aqidah alWāsițiyyah, (Dammām: Dar Ibnu Jauzî, Cet. 4, 1427 H), hlm. 57.

19 Abu Yusuf, Kitab al-Kharrāj, Tahqî̀q Abu Maryam 
1) Ușman bin 'Affān -radiyallahu'anhu-Syubhat dan Jawaban

a) Rasulullah Akan Menikahkannya dengan Putrinya yang Lain. Ada riwayat dalam hal ini tetapi lemah ${ }^{20}$.

b) Uṡmān Dibaiat Karena Usia. Benar Uṡmān diba' iat ketika berumur 70 tahun. Namun alasan yang tepat menurut Ahlu Sunnah wa al-Jamā'ah adalah didahulukannya Uṡmān atas Ali, berdasar hadis Ibnu Umar ${ }^{21}$ dan hadis Muhammad bin Ali al-Hanafiyyah dari Ali ${ }^{22}$.

c) Kepemimpinan Uṡmān Berbeda dengan Umar Karena Usianya Sudah Lanjut Ketika Diangkat Menjadi Khalifah. Analisa ini kurang tepat. Ada beberapa faktor: 1) Perbedaan sifat dan watak keduanya, Umar yang cenderung keras dan Us̉mān yang cenderung pemalu dan pemaaf tapi bukan berati lemah. 2) Perbedaan keadaan antara dua masa dalam beberapa hal ${ }^{23}$.

d) Uṡmān Mendahulukan Keluarganya. Dimaksud keluarganya adalah Bani Umayyah. Usmān memiliki alasan dalam hal ini sebagaimana

Muhammad bin Ali al-Jîlānî, (Kairo: Maktabah Taufiqiyyah, Cet. 1, 2013), hlm. 139.

20 Aż-Żahabî, Siyar A'lām an-Nubalā Jilid II, Taḥqîq Khairi Sa'îd (Kairo: Maktabah Taufiqiyyah., Tt), hlm. 505. Muhaqqiqnya mengatakan bahwa sanadnya da' îf jiddan.

21 Imam Bukhārî, Șahịh Bukhārî, Tahquîq Khalîl Ma'mun Syîhāa (Beirut : Dar Al-Ma'rifah, Cet. 2, 1428 H) ḥadî̀ 3655 dan Abu Dawud, Sunan, hạadîs 4629.

22 Bukhārî, Șahiḥ, hạadîs 3671. Abu Dawud, Sunan, hadîs 4629

23 Uṡmān al-Khāmīs, Huqbah min at-Tārîkh (Kairo: Maktabah Imam al-Bukhārî, Cet. 4, 1429 H), hlm. 97.
Rasulullah memiliki alasan mengangkat pegawai dengan presentase terbanyak dari Bani Umayyah $^{24}$ sebagaimana Ali mengangkat banyak gubernurnya dari Bani Hasyim, keluarganya sendiri. Ali mengangkat 6 gubernur dari keluarganya, Uṡmān mengangkat 5 gubernur dari Bani Umayyah. Ketika Uṡmān meninggal tinggal 3 gubernur ${ }^{25}$. Jika Uṡmān dicela, mengapa Rasulullah dan Ali juga tidak dicela?.

e) Us̉mān Lemah dan Tidak Tegas. Rasulullah mengatakan bahwa Uṡmān pemaaf $^{26}$, bukan berarti lemah dan tidak berdaya ${ }^{27}$. Uṡmān menolak tawaran pembelaan yang banyak termasuk Mu'āwiyah yang menawarkan penjagaan untuk Usmān atau memindahkan ibukota ke Damaskus, namun Uṡmān menolak $^{28}$. Uṡmān juga menghukum saudara tiri dari ibunya, al-Walîd bin Uqbah dalam perkara $k$ hamr $^{29}$. Jika Usmān tidak tegas dan mendahulukan keluarganya, bagaimana mungkin ia menghukum

24 Ibnu Taimiyah mengatakan bahwa pegawai Rasulullah banyak berasal dari Bani Umayyah karena jumlah mereka disamping kemuliaan dan jiwa kepemimpinan mereka. Ibnu Taimiyyah, Minhāj al-Sunnah Jilid VI, Tahqî̀ Muhammad Rusyād Sālim, (Riyadh: Dar alFaḍilah. Tt), hlm. 192.

25 Tārîkh Ibn Khayyat hlm. Y.1_r.. sebagaimana dinukil Uṡmān Al-Khāmīs, Huqbah, hlm. 102.

26 Muslim bin al-Hajjāj, Șahih Muslim, Tahqî̀q Khalîl Ma'mun Syịhāa, (Beirut : Dar al-Ma'rifah, Cet. 2, 1428 H) Kitāb Faḍāil Șaḥābat hạadîs 2401.

27 Uṡmān Al-Khāmīs, Huqbah, hlm. 143.

28 Ibnu Kas̄īr, Al-Bidāyah wa an-Nihāyah Jilid VII, Isyräf Mușțafa al-Adawî (Kairo: Dar Ibnu Rajab, Cet. 1, $1425 \mathrm{H})$, hlm. 322.

29 Muslim, Sahịh, Kitāb Hudūd 4432. 
saudara tirinya?.

f) Harta Kekayaan Dibagibagikan Tanpa Kontrol. Hal ini perlu dibuktikan dan diperinci lagi.

g) Uṡmān Membagikan Tanah.

(1) Uṡmān Membagikan

Tanah. Ini bukan celaan tetapi justru kebaikan Uṡmān. Uṡmān mengikuti Rasulullah, Abu Bakar dan Umar. Pada masanya semakin banyak tanah yang ditinggalkan oleh pemiliknya terutama tanah terbuka sehingga Uṡmānmembagikannya agar tanah tersebut produktif dan tidak terbengkalai ${ }^{30}$. Hal ini dalam figh disebut $i q t \bar{a}^{\prime 31}$ yang ma'sū $r$ dari Rasulullah, al-Khulafā' ar-Rāsyidūn dan menjadi ijma' ulama' ${ }^{32}$

(2) . Ali Menarik Pemberian. Syaikh Rabî' mengatakan kisah ini tidak benar disandarkan kepada $\mathrm{Ali}^{33}$. Riwayat dusta ini ada di Nahj al-Balāgah ${ }^{34}$ karya Muhammad bin al-Husain bin Mūsa al-Kāzim dan juga

30 Akram Ḍiyā' al-'Umarî, 'Așr al-Khilāfah ar-Rāsyidah, (Riyadh: al-Ubaikān, Cet. 6, 1430 H), hlm. 243.

31 Maknanya menurut Ibnu 'Ābidīn adalah apa yang diberikan oleh Imam(pemimpin). Atau tanah yang diberikan Imam agar dijaga atau dimanfaatkan orang yang menggunakannya. "iqțā", al-Mausūah alFiqhiyyah Jilid 6, hlm 81.

32 Rabî' bin Hādi Al-Madkhalî, Matāa 'in Sayyid Quṭb fi Așhabi Rosulillah dalam Al-Majmū' al-Mumajjd fi ar-Rad 'ala Sayyid Qutb wa Akhihi Muhammad. Ed. Ahmad bin Yahya al-Zahrānî, (Kairo: Dar alIstiqāmah, Cet. 1, 1430 H), hlm. 384.

33 Rabî' bin Hādi al-Madkhalî, Mațā'in hlm. 384.

34 Abu al-Hasan Muhammad bin Husain, Nahj AlBalāgah, Tahquîq Fāris al-Hassūn, (Qum dan Najaf: Markaz al-Abhas al-Aqāidiyah, Cet. 1, 1419 H), hlm. 50. penjelasannya yang ditulis oleh Ibnu Abi alHadīd Al-Mu'tazilî.

2) Ali bin Abi Țalib -radiyallahu'anhu- Syubhat dan Jawaban

a) Perang Jamal. Aisyah. Talhah dan Zubair tidak memberontak. Mereka meminta agar pembunuh Uśmān segera diadili35. Mu'āwiyah juga demikian $^{36}$. Ali ingin keadaan membaik terlebih dahulu karena bisa melihat kemaslahatan lebih besar pada waktu itu, sehingga tidak langsung memproses darah Uṡmān. Mu'āwiyah sebagai khalifah (41 H-61 $\mathrm{H})$ hingga meninggal tidak diceritakan mengadili pembunuh Uṡmān, karena Mu'āwiyah bisa melihat kemaslahatan yang sudah dilihat Ali sebelumnya ${ }^{37}$. Kemaslahatan ini pula menjadikan Rasulullah urung mencambuk Abdullah bin Ubay bin Salul; penyebar fitnah hadis al-ifk. Karena mencambuknya akan menyebabkan kerusakan lebih besar. $^{38}$ Mengenai Aisyah, tidak benar kalau Aisyah ditawan oleh Ali. Ia bersama saudaranya, Muhammad bin Abu Bakar masuk ke kota Bașrah dan tinggal di rumah Abdullah bin Khalaf al-Khuzzā'i ${ }^{39}$. Ali memuliakan,

35 Ibnu Ḥajar. Fath-al-Bārî Jilid XVI, (Dammām : Ibnul Jauzî, Cet. 1, 1425 H), hlm. 518.

36 Lihat ta'liq Muhibbuddīn al-Khațīb dalam Ibnu alArabî, al-'Awāṣim min al-Qawāșim, hlm. 162-163.

37 Us̉mān al-Khāmīs, Huqbah, hlm. 133-135.

38 Bukhārî, Șaḥ̄ḥ, Kitāb al-Magāzî ḥadîs 4141.

39 Ibnu Kas̄īr, Al-Bidāyah wa an-Nihāyah Jilid VII, hlm. 19. 
menyiapkan akomodasi 'Aisyah hingga ke Makkah bersama Muhammad bin Abu Bakar ${ }^{40}$. Fakta adanya perselisihan antara Ali dengan 'Aisyah sudah dikabarkan oleh Rasulullah sebelumnya ${ }^{41}$. Țalhạ dan Zubair keadaannya tidak seperti dalam buku ini, Zubair keluar dari barisan ketika ia sadar bahwa ia salah, ia diingatkan Ali dengan hadis Rasulullah bahwa ia memerangi Ali dan berlaku zalim ${ }^{42}$ sehingga ia keluar dari barisan dan bukan lari. Di Wādī as-Sibā'43 Zubair dibunuh oleh 'Amrū bin Jurmuz, Fuḍālah bin Hāābis dan $\mathrm{Nafi}^{\prime 44}$. Ali ketika mengetahui terbunuhnya Zubair ia marah dan mengatakan" Beritahu bahwa pembunuh Zubair bin Shafiyyah (masuk) neraka". Țalhạ terbunuh karena anak panah yang menancap di lututnya hingga darah mengalir dan meninggal karena itu ${ }^{45}$. Ali dan 'Aisyah menyesal atas apa yang terjadi ${ }^{46}$, bahkan Ali terkadang memuji yang tidak ikut perang tersebut ${ }^{47}$.

b) Perang Siffīn. Tidak benar Ali tertipu, Ali berijtihad

40 Ibid, hlm. 21.

41 Musnad Ahmad Jilid VI, hlm. 393. Sebagaimana dinukil Uṡmān al-Khāmīs, Huqbah, hlm. 133.

42 Lihat riwayat berkaitan sebab keluarnya Zubair dari pertempuran dalam Ibnu Kasīin, Al-Bidāyah wa anNihāyah Jilid VII, hlm. 15-16.

43 Ibid, hlm. 17.

44 Ibid, hlm. 25.

45 Ibid, hlm. 23.

46 Aż-Żahabî, Siyar A'lảm al-Nubalā' Jilid II, Taḥî̀q Khairî Sa'îd, (Kairo: Maktabah Taufiqiyyah, T.t.), hlm. 537.

47 Ibnu Taimiyyah, Majmu' Fatāwa Jilid XXXV, Tahqî̀q Khairî Sa'îd, (Kairo: Maktabah Taufiqiyyah, T.t.), hlm. 37. memerangi Mu'āwiyah agar Mu'āwiyah dan Syam membaiat Ali sebagai khalifah $^{48}$. Mu'āwiyah tidak akan mengumpulkan pasukan jika Ali tidak memeranginya karena ia hanya ingin pembunuh Uṡmān diadiliti ${ }^{4}$. Ketika perang berkobar 'Amrū bin al-'Ạṣ mengusulkan

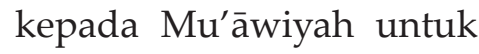
mengangkat mushaf agar perang terhenti dan mereka berhukum dengan alQur'an ${ }^{50}$. Akhirnya perang terhenti dan disepakati perundingan Daumatul Jandal. Pihak Ali diwakili oleh Abu Mūsa al-Asy'arî -termasuk pihak yang tidak ikut dalam fitnahdan pihak Mu'āwiyah diwakili oleh 'Amrū bin al-'Āṣ. Perundingan ini diikuti oleh beberapa șāhāât diantaranya Ibnu Umar. Mu'āwiyah datang ke tempat ini, sedangkan Ali tidak, kemungkinan karena ancaman Khawarij yang semakin merajalela.

c) Ali Memecat Gubernurgubernur Uṡmān Karena Dianggap Pergolakan Terjadi Karena Keteledoran Mereka. Beberapa șahābat mengisyaratkan pada Ali agar meneruskan jabatan para gubernur Uṡmān, diantara mereka adalah Abdullah bin Abbās dan al-Mugīrah bin Syu'bah ${ }^{51}$. Namun Ali berijtihad

\footnotetext{
48 Abu Dāwud, Sunan, Kitāb as-Sunnah hadis 4666. AlAlbānî mengatakan "Isnadnya șahị̣̣̄”.

49 Ibnu Kas̄īr, Al-Bidāyah wa an-Nihāyah Jilid VII, hlm. 36.

50 Ibid, hlm. 51-52.

51 Ibid, hlm. 390.
} 
untuk mengganti mereka ${ }^{52}$. Beberapa pegawai Usmān meninggalkan jabatannya segera setelah Usmān terbunuh. Kurang arif melemparkan tuduhan pada mereka, karena terlalu banyaknya faktor perselisihan tersebut.

d) Ali Menarik Kembali Pajak Sebagaimana Pada Masa Umar. Perlu dirinci dan dijelaskan lebih lanjut.

e) Hasan lemah. Hasan tidak lemah. Rasululllah memuji Hasan atas perdamaiannya ${ }^{53}$.

\section{Daulah Umayyah}

1. Syubhat dan Jawabannya

a. Mu'āwiyah dan khilafah. Dalam buku ini dinyatakan " Mu'āwiyah bin Abi Sufyān melihat bahwa pendukung Hasan bin Ali tidak begitu banyak, maka upaya yang dilakukan adalah berusaha merangkul kekuatan baik dari kawan maupun lawan politiknya untuk merebut kekuasaan ${ }^{54}$. Dari pernyataan penulis buku ajar ini kita biasa mengambil beberapa kesimpulan:

1) Mu'āwiyah melihat peluang untuk merebut kekuasan dari Hasan dengan segala cara. Hasan menyerahkan pemerintahan kepada Mu'āwiyah murni atas inisiatif sendiri tanpa ada paksaan ${ }^{55}$, tidak pula Mu'āwiyah. Bahkan Hasan secara pribadi tidak setuju dengan ayahnya sendiri, Ali yang memerangi $\mathrm{Mu}^{\prime}$ āwiyah ${ }^{56}$.

52 Ibid.

53 Bukhārî, Șaḥīh, Kitāb aṣ-Ṣuḷ̣ ḥadî̀ 2704

54 Sugiyono dan Muhammad Sulaiman, Perjalanan Sejarah Kebudayaan Islam 1, (Solo: Aqila, 2013), hlm. 89.

55 Bukhārî, Șạihị ḥadîs 2704.

56 Ibnu Kas̄īr, al-Bidāyah wa an-Nihāyah Jilid VIII,
2) Hasan pendukungnya sedikit. Hal ini perlu dibuktikan lebih lanjut. Ali setelah tahkim keluar hendak meminta ba'iat kepada penduduk Syam dengan membawa pasukan 40.000 pasukan dibawah Qais bin Sa'ad bin Ubadah. Setelah Ali meninggal mereka membai'at Hasan. Dari sini diketahui pendukung Hasan banyak, namun Hasan menginginkan perdamaian dan Qais tidak taat padanya, maka diganti Abdullah bin Abbas ${ }^{57}$. Penggantian ini menunjukkan itikad baik Hasan untuk perdamaian $^{58}$.

3) Mu'āwiyah mempergunakan segala cara untuk merebut kekuasaan termasuk diantaranya merangkul kawan dan lawan politiknya untuk sampai ke tampuk kekuasaan. Mu'āwiyah tidak seperti itu, dalam Sahihh $B u k h \bar{a} r \imath^{59}$ disebutkan perkataan Mu'āwiyah yang khawatir jika darah tertumpah akan menyengsarakan keluarga yang terbunuh. Riwayat itu juga menjelaskan bagaimana Abdurrahman bin Samurah dan Abdullah bin 'Āmir bin Kuraiz menawarkan diri (sebagai duta Mu'āwiyah kepada Hasan untuk damai) dan Mu'āwiyah setuju. ${ }^{60}$ Ibnu Hajar menjelaskan bahwa hadis ini menunjukkan kebaikan Mu'āwiyah kepada rakyat ${ }^{61}$.

4) Menumbuhkan fanatisme Arab, bahkan lebih sempit lagi fanatisme Qurays. Semua

Isyrāf Mușțafa al-Adawî (Kairo: Dar Ibnu Rajab, Cet. 1, $1425 \mathrm{H})$, hlm. 3.

57 Ibnu Ḥajar, Fath-al-Bārî Jilid XVI, hlm. 529.

58 Uṡmān al-Khamîs, Huqbah, hlm. 155.

59 Hadî̀ 7109 dan 2704

60 Ibnu Ḥajar, Fath-al-Bārî Jilid XVI, hlm. 531.

61 Ibid, hlm. 529. 
orang sama dalam Islam sama kecuali takwa mereka ${ }^{62}$. Tidak dinafikan terjadi beberapa gejolak kesukuan pada masa Umayyah sebagaimana terjadi di banyak tempat di dunia ini, dulu dan sekarang juga. Allah meletakkan aturan bahwa kepemimpinan berada di tangan Qurays sebagaimana hadis Rasulullah dari Abdullah bin Umar $^{63}$ dengan hikmah yang banyak dan sudah dijelaskan ulama ${ }^{64}$. Penulis menyayangkan pernyataan penulis buku ini yang cenderung tendensius dan bernada "curiga" terhadap kaum Muslim sendiri. Bani Umayyah juga memberikan jabatan kepada beberapa orang mawali65. Hal ini pilihan berbarakah yang menjadikannya jauh lebih baik dari daulah semasanya sebagaimana dikatakan Ubaidullah as-Sindi yang notabene bukan orang Arab ${ }^{66}$.

5) Mengadu domba kabilahkabilah yang menjadi lawan politiknya. Apakah ada bukti dari tuduhan ini?. Perjalanan hidupnya baik. Kekuasaannya adalah rahmat dengan persaksian Rasulullah. Ibnu

62 Q.S. Al Hujurāt 49:13.

63 Bukhārî, Șahihh, hadis 3501 dan 7140. Muslim, Sahịh, hadis 4681 .

64 Mengenai imāmah di tangan Qurays, lihat Ibnu Ḥazm, al-Fiṣl fi Milal wa Ahwā wa an-Nihal Jilid II, (Beirut: Dar al-Ma'rifah, 1406 M), hlm. 89.

65 Bermakna orang bukan Arab yang menjadi budak karena tawanan perang atau jual beli budak. Istilah ini kemudian meluas menjadi setiap orang non Arab yang masuk Islam dan dinisbahkan kepada kabilah tertentu secara sosial dan bukan karena darah atau nasab. Lihat Amjad Mamdūh al-Fā'ūri, Nazrah al-Qabāil li al-Mawāli fi 'Așr al-Umawi dalam Majallah Adab alBasra No. 55:192.

66 Imam dan Khatib Masjidl Haram dan pengajar di Ma'had Haram al-Makkî (w. 1392 H). Abdurrahman al-Mu'allimî al-Yamanî, al-Qāid ala Șaḥiḥ al-I'tiqad. Ta'lìq Syaikh Abdurrazzāq Hamzah dan Muhammad Nașiruddîn al-Albanî. (Beirut: Maktab al-Islami. Cet. 3, 1404 H), hlm. 249.
Taimiyah mengatakan ia adalah raja terbaik dalam Islam dengan persaksian para ulama ${ }^{67}$.

6) Membangun kekuatan militer di Damaskus yang hanya tunduk pada pemerintahannya, dan dibentuk juga tentara bayaran dari penduduk asli Damaskus dan para imigran Arab.

7) Politisasi pembunuhan Uṡmān. Hal ini tidak benar. Mu'āwiyah sebagai keluarga meminta darah Us̀mān diselesaikan. Hal ini sama dengan yang dilakukan 'Āisyah, Țalhah, dan Zubair hingga membawa petaka Perang Jamal. Perselisihan Mu'āwiyah dan Ali "hanya" dalam tatacara menyelesaikan pembunuhan Uṡmān namun berujung petaka Perang Șiffīn. Mu'āwiyah melakukan hal tersebut murni karena ijtihadnya, begitu pula pihak 'Áisyah dan Ali. Hadist Rasululullah menjelaskan bahwa Ali berada di pihak yang benar dan yang memeranginya sudah keliru dalam ijtihadnya, mereka semua adalah orangorang yang paling layak untuk berijtihad. Namun ada yang benar dan ada yang keliru dalam berijtihad. Abbāsiyah yang tidak suka dengan Daulah Umayyah meletakkan tulisan di pintu masjid-masjid di kota Baghdad "Orang terbaik setelah Rasulullah adalah Abu Bakar, kemudian Umar, kemudian U๑mān kemudian Ali, kemudian Mu'āwiyah; pamannya kaum Muslim ${ }^{68 "}$. Hal ini dikatakan Ibnu al-

67 Ibnu Tamiyah, Majmu' Fatāwa Jilid IV, hlm. 307.

68 Dikatakan demikian karena Mu'āwiyah adalah saudara dari Romlah binti Abu Sufyan yang lebih dikenal dengan kunyahnya Ummu Habibah. 
Arabi $\hat{1}^{69}$ yang mengetahui persis keadaan Baghdad ketika masuk ke kota tersebut dalam perjalanan ilmiahnya dari Andalus.

8) Perjanjian damai dengan tujuan mencari jalan terbaik untuk menyusun langkah berikutnya. Penulis menjawab bahwa maksud hal ini perlu dirinci. Kalau yang dimaksud adalah tahkim, maka perlu dirinci lebih lanjut.

b. Jawaban Atas Latar Belakang Runtuhnya Daulah Umayyah

1) Mengenai khalifah. Secara umum khalifah Umayyah adalah orang-orang yang cakap, beberapa dari mereka memang memiliki kekurangan. Namun tidak lantas menutupi jasa dan kebaikanm terutama Yazid bin Mu'āwiyah dan Marwan al-Hakam. Secara umum para khalifah adalah imam shalat lima waktu, mengangkat panji jihad. Jihad dan penyebaran Islam yang mereka lakukan barangkali tidak dapat disaingi daulah apapun setelahnya mengingat begitu gigihnya mereka dalam hal ini.

2) Mengenai pegawai. Tidak dipungkiri sebagian pegawai yang berlebihan tugasnya dengan berbagai tujuan keduniaan semisal Muslim bin Uqbah al-Mirrî dalam peristiwa Harrah di Madinah, Ubaidillah bin Ziyād kepada Uṡmān di Karbala, dan kezaliman Ḥajjāj bin Yusuf aś-Saqafí. Do'a orang terzalimi tidak ada penghalang antaranya dengan Allah. Namun proporsional tetap menjadi sandaran dan tidak

69 Ibnu al-Arabî, al-'Awāṣim, hlm. 213. terlalu membesar-besarkan masalah.

3) Banyaknya aliran. Salah satu syarat penting adab sejarawan adalah judgment yang tepat dan proporsional. Khawārij yang selalu memberontak karena memang demikian tipikal mereka-, Syi'ah, atau kelompok yang lain hanyalah bagian kecil dari masyarakat Islam secara keseluruhan. Kedua golongan; Syi'ah dan Khawārij memang demikianlah adanya. Kalau yang lebih mulia dari para khalifah Daulah Umayyah saja mereka tentang -yaitu Ali- apalagi para khalifah Daulah Umayyah yang jelas keutamaannya di bawah Ali. Begitu juga konflik suku memang ada, misalkan di Marj ar-Rāhi@ $(64 \mathrm{H})^{70}$ dan konflik antara Arab Muøar dan Yaman di Baruqan di wilayah Khurasan $^{71}$. Namun tidak adil kalau dikatakan bahwa "banyak" yang tidak suka kepada Daulah Umayyah.

4) Standar suksesi. Tidak dipungkiri bahwa sistem suksesi kekhalifahan menimbulkan perselisihan. Benar jika sistem syura dalam suksesi seperti masa al-khulafä' ar-rāsyidūn ditinggalkan dan diganti dengan sistem putra mahkota hingga menimbulkan keengganan sebagian kalangan, misalkan dalam ba'iat Yazid ${ }^{72}$.

70 Adebiyi Jelili Adegboyega dan Hassan Ahmed Ibrahim, The Concept of Al-I'tibar and The Fall of the Umayyads: An Explicatory Appraisal and its Contemporaneity in Understanding The Present Travail of Muslims dalam World Journal of Islamic History and Civilization Vol. 1, No. 1: 54.

71 Huda Nuri, Wulāt al-Khurasān Khilāl 'Aṣr al-Khilāfah al-Umawiyah dalam Majallah Jāmi'ah al-Anbar li alUlūm al-Insāniyah No. 1:250.

72 Ibnu Taimiyah, Majmu' Fatāwa Jilid III, hlm. 260. 
Sebagaimana juga lazim diketahui adanya perselisihan antara keluarga Sufyān dan Marwan. Sesungguhnya bentuk pemerintahan; termasuk sistem suksesi dengan putra mahkota akan mengikuti keadaan masyarakat, sebagaimana keadilan, harga barang, pusat pemerintahan juga mengikuti keadaan keimanan masyarakat pada waktu itu ${ }^{73}$. Karena itu Ibnu Khaldūn menjelaskan perbedaan zaman menuntut perbedaan keadaan, termasuk tata cara suksesi pada masa Umayyah dan Abbasiyah. Sehingga hal ini tidak tercela, namun kondisi yang menuntut demikian $^{74}$. Ulama Islam membolehkan kepimpinan orang yang lebih rendah derajat takwa dan ilmunya atas yang lebih tinggi, salah satu dalilnya hadîs Bukhārî diatas ${ }^{75}$. Cara ini memang berbeda dengan masa al-khulafā' ar-rāsyidūn dengan syura yang jelas paling afdal. Namun sistem ini jauh lebih baik dari sistem sekarang dengan pemilihan langsung.

5) Diskriminasi. Islam tidak mengenal diskriminasi, diskriminasi pada masa ini terjadi pada kalangan tertentu dan bukan sikap resmi negara, hingga muncul banyak ulama non-Arab atau pegawai nonMuslim.

73 Abdul Mālik Ramaḍanî, Kamā Takūnū Yuwalla 'Alaikum, (Kairo: Dar al-Furqān, Cet. 4, Tt.) hlm. 74. Mengenai pusat pemerintahan, terdapat pendapat lain yang menyebut perpindahan tersebut karena faktor dukungan yang lebih besar di ibukota yang baru dibandingkan ibukota yang lama. Lihat Othman Ismael al-Tel, Islamic State View and Adminstration of Jerussalem after the Muslim Conquest of the City dalam World Journal of Islamic History and Civilization, Vol. 2, No. 4:252.

74 Ibnu Khaldūn, Muqaddimah, hlm. 263-264.

75 Bukhārî, Sahịh hạị̂s 7109 dan lainnya.
6) Syi'ah. Ibnu Taimiyah mengatakan mereka adalah orang yang paling banyak dustanya dan kejahilannya ${ }^{76}$. Orang yang cerdas mengetahui pengngkhianatan mereka pada Ali, Husain bahkan mengkafirkan Abu Bakar dan Umar. Jika orang semulia Abu Bakar dan Umar dikafirkan, Syiah akan lebih mudah merendahkan penguasa Daulah Umayyah.

7) Gerakan Abbāsiyah. Gerakan Abbāsiyah muncul di awal abad II Hijriah hingga menjadi sebab penting runtuhnya Daulah Umayyah tahun $132 \mathrm{H}$.

\section{KESIMPULAN}

Penelitian ini menghasilkan beberapa kesimpulan, diantaranya: 1). Cara orisinil dalam memahami sejarah Islam adalah kembali kepada kaidah khas Islam. Khusus dua masa ini dengan titik tolak akidah terhadap șahāābat, 2). Distorsi/tahrīf bermakna usaha untuk mengubah data atau tafsiran data tersebut dengan tujuan tertentu. Distorsi ini pada masa awal penulisan sejarah Islam distorsi terutama dimotori oleh Syi'ah dengan menyebutkan riwayat-riwayat dusta. Distorsi pada masa sekarang terutama dipengaruhi kuatnya hegemoni orientalisme, 3). Perselisihan di antara șahāābat pada masa Ali terjadi karena perbedaan cara menyelesaikan kematian Uṡmān, namun banyak sejarah masa ini yang terdistorsi dan banyak menjadi sebab perselisihan hingga sekarang.

Sarannya adalah: 1). Agar kaum Muslim kembali kepada agamanya secara kaffah terutama dengan mengimplementasikan tauhid, dalam hal ini akidah terhadap șahāābat, 2). Perlu digiatkannya studi sejarah Islam yang orisinil dan murni baik kuantitas maupun kualitasnya, 3). Perlunya

76 Ibnu Taimiyyah, Majmu' Fatāwa Jilid IV. Tahqû̀q Khairî Sa'îd, (Kairo: Maktabah Taufiqiyyah, T.t.), hlm. 544. 
studi yang lebih intensif tentang sejarah dalam dua masa ini dengan metode yang orisinil, 4). Perlunya studi lanjutan yang orisinil terhadap distorsi dalam fase sejarah Islam yang lain semisal tentang Abbāsiyah dan lainnya, 5). Perlunya perbaikan buku pegangan anak didik dalam pendidikan Islam di semua jenjang, begitu juga buku ajar sejarah Islam.

\section{DAFTAR PUSTAKA}

Adegboyega, Adebiyi Jelili dan Ibrahim, Hassan Ahmed. 2011. The Concept of Al-I'tibar and The Fall of the Umayyads: An Explicatory Appraisal and its Contemporaneity in Understanding The Present Travail of Muslims dalam World Journal of Islamic History and Civilization Vol.1, No.1:54.

Amaḥzūn, Muhammad. 1429 H. Harakah al-'Ilmiyyah fi Bilād al-Hijāz fi al-'Așri al-Umawi dalam Abhasis fi al-Da'wah wa at-Tāriḥ wa al-Ijtima'. Cetakan Pertama. Kairo: Dār asSalām.

Al-Arabî, Qāọî Ibnu. 1396 H. Al- 'Awāṣim min al-Qawāṣim Tahqî̀q wa Ta 'lîq Muhibuddîn al-Khaṭ̂ib. Cetakan Keempat. Kairo: Matba'ah Salafiyah.

Arikunto, Suharsimi. 2007. Manajemen Penelitian. Jakarta: PT Rineka Cipta.

Al-Ba'labakî, Munîr. 2006. al-Maurîd al-Qarî̉. Beirut: Dār al-'Ilm Li al-Malāyîn.

Bukhārî, Muhamad bin Ismā’̂̀l. 1428 H. Șāhîhh al-Bukhārî. Tahqî̀q Khalîl Ma'mun Syîhāă. Cetakan Kedua. Beirut : Dār al-Ma'rifah.

Dawud, Abu. 1427 H. Sunan Abi Dawud. Taḥkîm wa Ta’lîq al-Albānî. Cetakan Kedua. Riyadh: Maktabah Ma'ārif.

Al-Fā'ūri, Amjad Mamdūh. 2011. Naẓrah al-Qabāil li al-Mawāli fi 'Așr al-Umawi dalam Majallah Adab al-Basra No. 55:192.

Ḥajar, Ibnu. 1425 H. Fath al-Bārî Jilid XVI. Cetakan Pertama. Dammām: Dār Ibnu al-Jauzî. . 1431 H. Nuzhah an-Nazar. Tahqî̀q Nuruddîn 'Itr. Cetakan Pertama. Kairo :

Dār al-Bașảir.

Ḥazm, Ibnu. 1406 H. Al-Fiṣal fi Milal wa al-Ahwā' wa an-Niḥal Jilid 3. Beirut: Dār al-Ma'rifah.

'Iyāọ, Qāḍ̂i. 1404 H. Asy-Syifă’ bi Ta'rîf Huqūq al-Muṣtafa Jilid 2. Tahqîq Bajawî. Berikut: Dār al-Kitab al-Arabî.

Al-Jaburî, Syakir dan Khalaf, Nada Zaidan. 2013. Al-Ulūm ad-Dîniyyah wa Tațawwuruhā fi 'Așr al-Umawi dalam Majallah ad-Dirāsāt at-Tārikhiyyah wa al-Ḥaḍariyyah Vol. 5, No. 16: 122.

Kasîir, Ibnu. 1425 H. Al-Bidāyah wa an-Nihāyah Jilid VII. Isyrāf Muștafa al-'Adawî. Cetakan Pertama. Kairo: Dār Ibnu Rajab.

1425 H. Al-Bidāyah wa an-Nihāyah Jilid VIII. Isyräf Muștafa al-'Adawî. Cetakan Pertama. Kairo: Dār Ibnu Rajab.

Ibnu Khaldūn. 1431 H. Tārîkh Ibnu Khaldūn Jilid I (Muqaddimah). Beirut: Dār al-Fikr.

Al-Khamîs, Uṡmān. 1429 H. Hiqubah min at-Tārîkh. Cetakan Keempat. Kairo: Maktabah alImam al-Bukhārî.

Kuntowijoyo. 2013. Pengantar Ilmu Sejarah. Cetakan Pertama. Yogyakarta: Tiara Wacana.

Al-Madkhalî, Rabî' bin Hādi. 1430 H. Mațā' in Sayyid Quṭb fi Așhabi Rosulillah dalam al-Majmū' al-Mumajjad fi ar-Rad 'ala Sayyid Quṭ wa Akhihi Muhammad. Ed. Ahmad bin Yahya az- 
Zahrānî. Cetakan Pertama. Kairo: Dār al-Istiqāmah.

Mājah, Ibnu. 1429 H. Sunan Ibnu Mājah. Tahkîm wa Ta 'lìq Al-Albānî. Cetakan Kedua.

Riyadh: Maktabah Ma'ārif.

Majma' Lugawî al-Masrî. Tanpa Tahun. Mu'jam al-Wajîz. Tanpa Tempat. Tanpa Penerbit.

Manz̄ūr, Ibnu. 1419 H. Lisān al-Arab Jilid IV. Cetakan Ketiga. Beirut: Dār Ihyā Turās al-Arabî.

Al-Mu'allimî, Abdurrahman bin Yahya. 1404 H. Al-Qāid ila Șahîh al-I'tiqād. Ta'lîq Muhammad Nāsiriruddîn al-Albānî. Cetakan Ketiga. Beirut: Maktab al-Islamî.

Muslim, Imam. 1428 H. Ṣahîh Muslim. Tahqî̀ Khalîl Ma'mun Syîhā. Cetakan Kedua. Beirut : Dār al-Ma'rifah

An-Nasā'i, Imam. 1429 H. Sunan an-Nasā'i. Tahkî̀m wa Ta'lîq al-Albānî. Cetakan Kedua. Riyadh: Maktabah Ma'ārif.

Nazir, Moh. 1988. Metode Penelitian. Jakarta: Ghalia Indonesia.

Nuri, Huda. 2012. Wulāt al-Khurasān Khilāl 'Așr al-Khilāfah al-Umawiyah dalam Majallah Jāmi'ah al-Anbar li al-Ulūm al-Insāniyah No. 1:250.

Al-Qairuwānî, Ibnu Abi Zaid. 1423 H. Muqaddimah Risālah Ibnu Abi Zaid Al-Qairuwānî dalam Qaț al-Janā ad-Dānî. Cetakan Pertama. Kairo-Dammām: Dār Ibnu Affān-Dār Ibnu alQayyim.

Ramaḍānî, Abdul Mālik. Tanpa Tahun. Kamā Takūnū Yuwalla 'Alaikum. Cetakan Keempat. Kairo: Dār al-Furqān.

Sāhîn, Ḥamdi. 2001. Ad-Daulah al-Umawiyah al-Muftara Alaiha. Kairo: Dār Al-Qāhirah li alKitab.

Sugiyono dan Muhammad Sulaiman. 2013. Perjalanan Sejarah Kebudayaan Islam I. Solo: Aqila. As-Sulamî, Muhammad bin Șāmil. 1429 H. Manhaj Kitābah at-Tārîkh al-Islamî. Cetakan Pertama. Dammām: Dār Ibnu al-Jauzî. 